\title{
Online Experimentation in Education and Training
}

\author{
http://dx.doi.org/10.3991/ijep.v4i2.3481 \\ M. T. Restivo ${ }^{1}$ and A. Cardoso ${ }^{2}$ \\ ${ }^{1}$ University of Porto, Porto, Portugal \\ ${ }^{2}$ University of Coimbra, Coimbra, Portugal
}

\begin{abstract}
The increasing use of emergent technologies in industry, medicine, research, training and education attests to the relevance of their integration in teaching/learning approaches.
\end{abstract}

Online experimentation comprises remote and virtual experimentation also supported and complemented by other online tools that incorporate necessarily the use of emergent technologies.

The present work synthesizes the final outcomes of a project aiming to develop, use and disseminate Online Experimentation, funded by the Calouste Gulbenkian Foundation. Some application examples are given to illustrate the use of online experimentation on different contexts, such as secondary and higher education (STEM), lifelong learning or industrial training.

Index Terms - online experimentation; virtual reality; augmented reality; haptic interfaces; intelligent tutoring.

\section{INTRODUCTION}

Online experimentation is an important current topic, based on emergent technologies, like remote access to experimentation, virtual $2 \mathrm{D}$ and $3 \mathrm{D}$ experimentation, augmented reality applications, sensorial devices for remote or virtual reality interaction and other additional tools as serious games, videos and interactive videos, available through web platforms with intelligent tutoring functionality.

In our perspective its use in education is essential because everyone will be (or already is) involved everywhere by the "Internet of Things", at home, in the street, at work, in the health field, for entertainment, etc.

These aspects are involving us all and many of them are used for helping people to improve the conditions of their everyday life.

All this progress also brings other requirements - it brings the constant need of learning how to use and take advantage of those new tools. So it is essential to look at lifelong training.

Later retirement tendency and population aging, both in USA and in Europe, also contribute to intensify the need for lifelong training in the use of technologies [1-3].

Horizon 2020 defines, in its Pillar I "Excellent Science", the line of Future and Emerging Technologies (FET) [4], with areas as, for example:

- Support the growth of ICT innovative Creative Industries SMEs;
- Technologies for creative industries, social media and convergence;

- Technologies for better human learning and teaching;

- Advanced digital gaming/gamification technologies.

As a natural consequence of all these tendencies the dissemination and use of online experimentation in teaching/learning environments are vital. Many other additional advantages are also associated and are often presented in many works in the field.

The use of online experimentation and its dissemination have been goals of recent projects funded by Calouste Gulbankian Foundation (CGF) in recognition of the relevance of the topic.

The Experiment@Portugal project funded by CGF in 2010-2011 was the seed of the Portuguese consortium in online experimentation based in the remote and virtual labs of higher education institutions in Portugal, which are available in the platform pt.lab2go (http://pt.lab2go.net), the Portuguese version of platform lab2go (http://lab2go.net) [5].

"Experiment@Portugal-2012: Online experimentation contents", which will be briefly described in this work, has been devoted to develop documental, multimedia, virtual and augmented reality contents, remote experiments, intelligent tutoring modules and low cost prototypes of haptic devices to be added to some of those already existing resources available at the pt.lab2go platform.

The project aimed to increasingly involve emerging technologies in education and in lifelong training with resources adapted to engineering, science and industry areas. It is also intended to develop contents in the STEM (Science, Technology, Engineering and Maths) area.

The webpage experiment@portugal has been designed to disseminate and to promote the online experimentation (http://www.fe.up.pt/experimentaportugal) by offering diversified information in its contents. It has also been used for helping in the diffusion of concepts, following the international ontology recommended by the GOLC (Global Online Laboratory Consortium), http://onlinelab.org/. In addition, experiment@portugal also aims to share resources with Portuguese speaking countries.

At present, other objectives have already been accomplished such as:

- To intensify the cross-universities network on online experimentation by intensively joining two of the Portuguese consortium partners (University of Coimbra and University of Porto) with other consor- 
tia in the world as is the case of the NeRELa Tempus project [6], potentiating the promotion of intercultural collaborative student and teacher activities;

- To disseminate the cross-collaboration in online experimentation between university-secondary schools, bringing teachers and students to cooperate in testing and evaluating the effectiveness of some of the developed resources as reported in different works [7] and in engineering education [8], both under submission;

- To attenuate the tendency for reducing experimental activity as a consequence of the Bologna process [911];

- To bring into the teaching-learning process the use of emerging technologies already in use in our everyday life;

- To contribute with online engineering experiments at lifelong learning level, mainly in good collaboration with industrial partners [12-15];

- To disseminate experimentation helping to overcome today's deficit of youngsters in Science and Technology [16];

- To promote the Experiment@International Conference series (exp.at'xx), and so the Online Experimentation, in the international community to a forum of discussion as it already successfully happened during the exp.at'13, held at University of Coimbra, September 18-20, 2013, Coimbra, Portugal, http://www.fe.up.pt/exp.at2013/.

In the next sections different approaches supported in emergent technologies and some outcomes of the Experiment@Portugal-2012 project will be briefly described.

\section{APPROACHES USING EMERGENT TECHNOLOGIES}

Experiment@Portugal-2012 has considered different approaches to online experimentation exploring emergent technologies as virtual and augmented reality, sensorial devices and additional tools as interactive videos and intelligent tutoring systems.

\section{A. Virtual and Augmented Reality}

Virtual and augmented reality can be used to generate environments as lifelike as possible [17]. Flight simulators, serious games, virtual access to a nuclear reactor under operation [18], virtual equipment as the virtual Michelson Interferometer [19] or virtual experiments about basics concepts of physics as the virtual inclined plane [20], are few examples among many others from different fields developed for learning and training activities. Theoretical concepts are also receiving important contributions from these computing potentialities as is the case of many studies in engineering, sciences, astronomy and medical areas, among many others.

Virtual reality is a very powerful and useful tool in the engineering field started in the 1960s and also with high relevance to online experimentation. A virtual experiment could be just a 2D simulation or a considerably more complex software program using high performance computers and new techniques to make possible the user interaction with the 3D world.

Augmented reality (AR) is a technique in which layers of virtual information are added to the reality, making it richer and more interesting and useful.
Pioneering works associated to AR are attributed to [21, $22]$. Since the very beginning, assembly tasks have been identified as being of interest for use of the AR technology. In 2003 the potential of AR in a car door assembly was reported in [23], while in 2012 AR was considered as relevant in complex assembly tasks [24].

Some application examples have been developed to illustrate the applicability of this technology to diverse systems and different learning/training contexts.

\section{B. Low Cost Haptic Device}

Concerning the interaction with equipment or virtual reality applications, haptic devices or kinesthetic systems, are, nowadays, used to improve the user's immersion. They allow the user to get perception of different sensorial information as a feedback result of the user interaction with the real or the virtual world. Feeling the real system or the virtual replica brings new dimensions to the cognitive process.

The concept and materialization of haptic devices appeared a long time ago, with the development and intensive use of flight simulators, the first having become available in 1928. More recently, haptic devices are being used for training purposes, either in industrial or in medical areas. For example, industrial assembly tasks have been responsible in the past for more than $60 \%$ of the total product cost, being for this reason one of the most studied processes in manufacturing industry [25] since the early stages.

The use of virtual reality (VR) with haptic interaction brought a very important degree of immersion with intuitiveness and interaction allowing the user to achieve efficiency in the planning and in the evaluation process and also in assembly/disassembly operations during the design process. Haptic devices can be used in many other areas and the availability of low cost versions is important for concept dissemination in the educational area.

Some works report how haptic devices have been used in education to bring benefits to dynamic system studies [26], or to the mechanical characteristics of the material [27] or, as is the case of the work described in [28], "nanomanipulator applications for tactile feedback and to manipulate objects such as viruses that are nanometersized".

The present development of a very low cost haptic device involves conception of such solution, its design, construction, testing and finally the communication protocol for interacting with a virtual application. Fig. 1 is the very first prototype of 1DOF haptic device, developed during the project and used as concept proof.

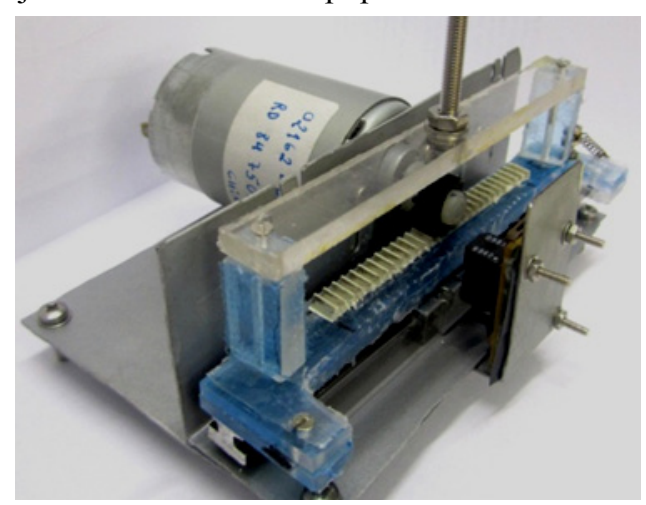

Figure 1. A low cost 1DOF haptic device. 


\section{Interactive Video}

In general terms a video can be considered as a message/story/content to be delivered in a linear sequence of images according to a specific associated screenplay. An interactive video can be defined as "the use of computer systems to allow proactive and random access to video content based on queries or search targets" [29, 30].

The interactive video improves the already recognized abilities of video content and interactive techniques and its use in education and training at different levels. Several examples can be found in a b-learning approach to health and safety (H\&S) subjects, in civil engineering construction at undergraduate and postgraduate levels, in engineering education and at industrial training level [29].

The examples developed in this project consider a set of videos assembled to reach a given objective and combined with various hypermedia elements, allowing the user to control his/her learning process.

\section{Intelligent Tutoring System}

To enhance the learning/training process, the specification and development of a Web platform should took into account the features of cooperation and virtual tutoring. The inclusion of an Intelligent Tutoring System (ITS) in a Virtual Learning Environment (VLE) could enhance the students' learning and understanding by meeting the students' expectations under specific constraints [31] and improve the VLE's characteristics by detecting possible systematic incorrect procedures.

ITSs consider, usually, four main modules: the domain model, the student model, the teaching model and the graphical user interface (GUI). Each module can be supported on Artificial Intelligence (AI) techniques, which use representations of the knowledge domain to understand the student's behavior and provide an intelligent response [32]. ITSs can provide advantages in the student's exploration and interaction by following the performance of the student in real time, using task planning to enhance the student learning and providing feedback, help and guidance to address the student immediate problems [33].

The technological evolution and advances in AI, neuroscience, psychology and cognitive science have brought significant and promising changes into the computer tutoring field. To assist learning in an intelligent manner, research has focused on addressing computer perception, the representation of the domain, the representation of the student mental state and the adaptability and sequence of responses (e.g. activities, problems and feedback) [34].

The main tasks involved in this project, concerning the VLE, were the specification and development of an ITS to acquire, store, represent and evaluate learner behavior and also to communicate with the student for enhancing his/her motivation and facilitating understanding.

\section{APPLICATION EXAMPLES}

To illustrate the use of these emerging technologies, some examples of applications of online experimentation developed during the Experiment@Portugal-2012 project are presented, considering the contexts of secondary education, engineering education and lifelong and industrial training.

\section{A. Applications for Secondary Education}

Fig. 2 shows a very simple example of the application of augmented reality based on a set of markers associated with different circuit elements (battery, switches and lamps), where the students can observe the intensity of light of various lamps as result of combining different onoff switches. The idea is to offer the possibility to insert different components in the electrical circuit and verify its operation when correctly set up.

Another example for secondary education was developed using an interactive video to explain the gravity pendulum movement. Fig. 3 shows the interface of a module on a basic concept of Physics, the oscillatory movement of the gravity pendulum which, in addition to the introduction of the associated concepts, is intended to illustrate the influence of the changes in body mass, wire length and gravity force in the pendulum's period of oscillation.

\section{B. Applications for Higher Education}

Some applications for engineering education have been developed. Fig. 4 shows the user interface layout of a virtual experiment based in selectable springs by predefinition of geometric parameters for different materials, which leads to different spring constants. The interaction with the virtual representation is done using the developed 1DOF haptic device, giving the possibility to the user to "feel" the force required to compress the spring according to different spring constants. This is an application oriented for freshmen students.

Other example deals with the seepage phenomenon using an approach based on an interactive video to combine different hypermedia elements which present a brief historical and technical perspective about dams, their structural configurations and main roles, with a special focus on embankment dams. Statistical data about large embankment dams is provided, as well as information about safety issues and accidents in this type of engineering works. Fig. 5 illustrates this application.

\section{Applications for Lifelong and Industrial Training}

Fig. 6 shows a model of a remote system for flatness evaluation based on AR. The user can observe from any angle, manipulate and interact with the virtual replica of that remote equipment, perform a test and even get the test results by email, for later evaluation. The flatness evaluation is a surface property with interest for lifelong learning activities or industrial training, as well as for mechanical engineering education.

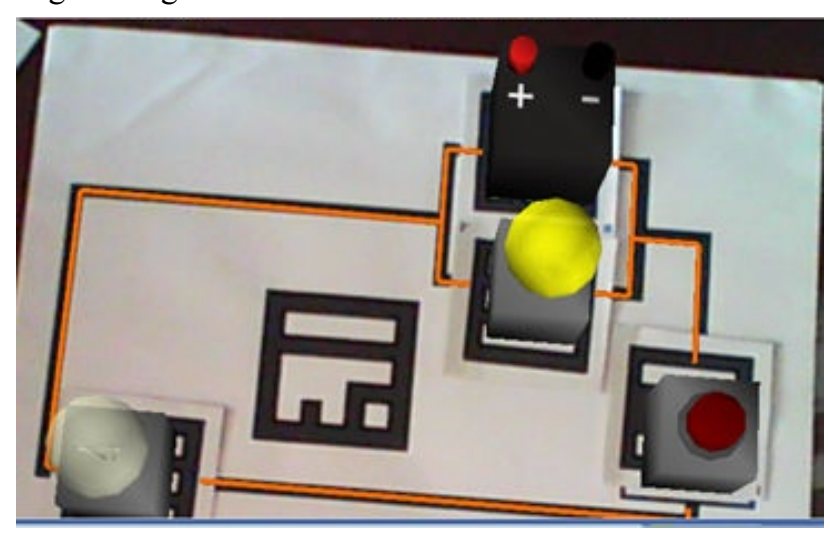

Figure 2. Electrical circuit using augmented reality. 


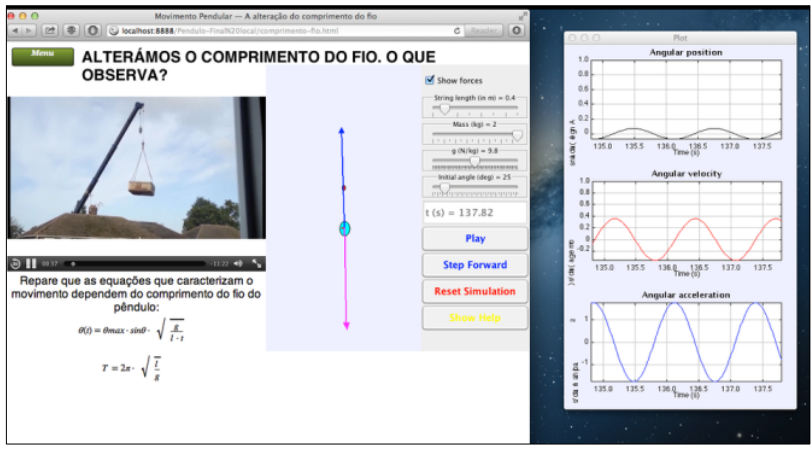

Figure 3. Interactive video for the gravity pendulum.

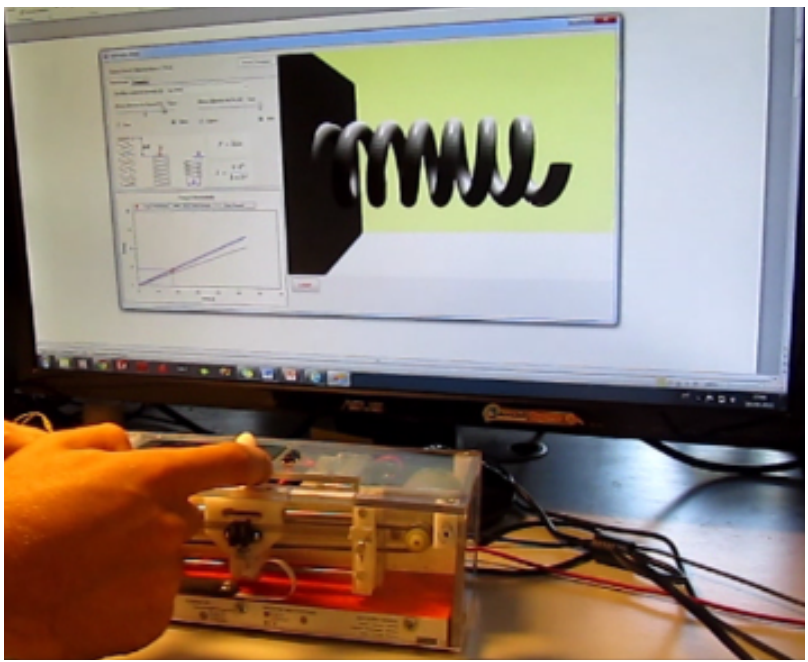

Figure 4. Virtual application with a haptic device for spring evaluation.

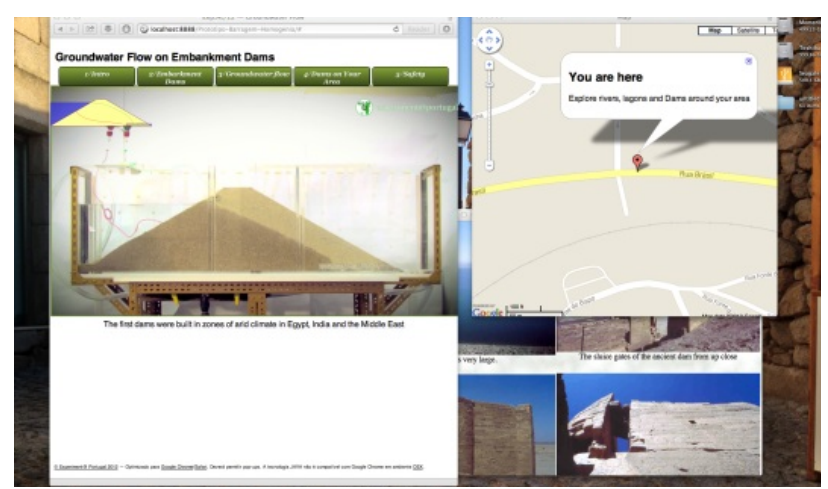

Figure 5. Interactive video for seepage phenomena

The characterization of nanoparticles, illustrated in Fig. 7 , is other topic with interest for industrial training. In fact, although nanoparticles are present, nowadays, in several applications, professionals need to update their education, since they have to deal with these materials and this subject was not present in their initial academic education.

\section{THE EXP.AT'13 INTERNATIONAL CONFERENCE}

In terms of dissemination of Online Experimentation, the organization of the $2^{\text {nd }}$ Experiment@International conference, exp.at'13, was the main contribution of the Experiment@Portugal-2012 project.

exp.at'13 brought together all type of emergent technologies and online tools for online experimentation. Its

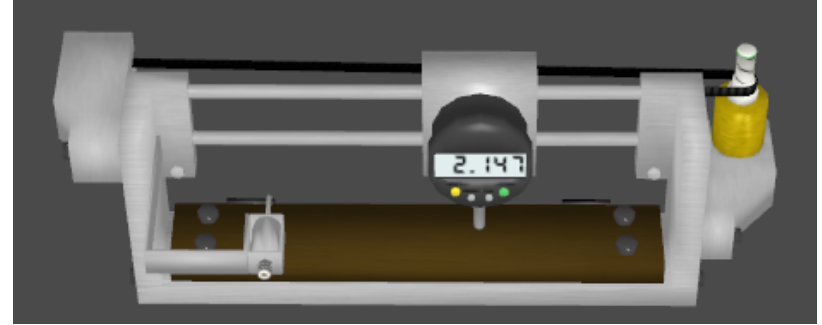

Figure 6. Reproduction of a remote system for flatness evaluation.

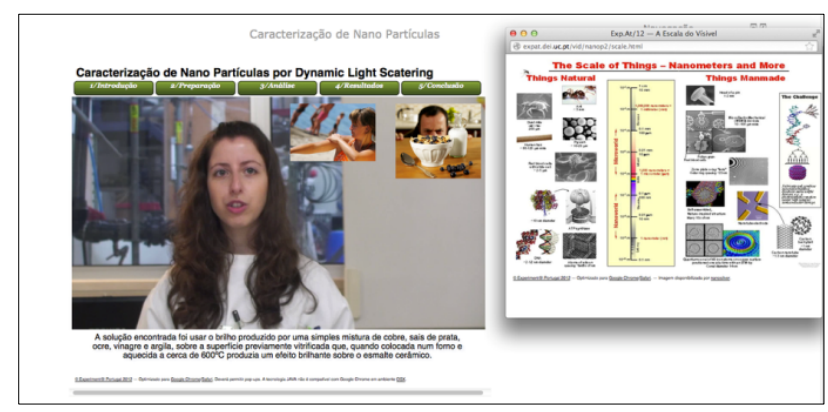

Figure 7. Interactive video: nanoparticles characterization.

objectives were to promote interactions involving engineers, researchers and professionals from different areas, for the advancement of science and technology, to open new perspectives for teaching and training activities, to inspire high quality research in online experimentation and to disseminate experimentation as a fundamental aspect to attract new persons to this field. The level of involvement of all participants was the real and most significant result of this event.

The exp.at'13 conference, held at University of Coimbra on September 18-20, 2013, included sessions for scientific presentations, plenary sessions with invited keynote speakers, industrial and thematic workshops, sessions for thematic discussion and to present the Horizon2020 EU program and two exhibition sessions, where works about the application examples described here were presented as live demonstrations.

\section{FINAL REMARKS}

This paper describes the some of the main outcomes of the project Experiment@Portugal-2012, concerning the use of emergent technologies and interaction using haptic devices to develop and promote the Online Experimentation in different learning/training contexts.

Some application examples for secondary and higher education and for lifelong and industrial training were presented. The $2^{\text {nd }}$ Experiment@ International Conference - exp.at'13 was also introduced.

The authors expect to have contributed with a new incentive for the online experimentation and to reinforce the opportunity of creating a new consortium to deal with the new opportunities and challenges of Horizon 2020 EU Program.

\section{ACKNOWLEDGMENT}

The authors wish to thank the Calouste Gulbenkian Foundation for funding the Experiment@Portugal-2012 project, acknowledge the support of University of Coimbra and University of Porto and the colleagues collaborating with the project in each university. 


\section{REFERENCES}

[1] (http://www.dol.gov/odep/pdf/NTAR Employer Strategies Repo rt.pdf, [Accessed 07 December 2013].

[2] (http://ec.europa.eu/health/population_groups/elderly/index_en.ht m), [Accessed 07 December 2013].

[3] M.T. Restivo and A. Cardoso, "Guest Editorial", International Journal of Online Enginering (iJOE), exp.at'13 Exhibition Session Special Issue, in print.

[4] http://ec.europa.eu/research/horizon2020/index en.cfm?pg=h2020 -documents [Accessed 07 December 2013].

[5] M.E. Auer, D.G. Zutin, C. Maier, M. Niederstätter, Lab2go - a Semantic Framework to Exchange and Publish Online Laboratories, REV 2010, pp. 133-138, Stockholm, Sweden, 2010.

[6] NeRELa Tempus project, http://eacea.ec.europa.eu/tempus/results compendia/documents/lis t-of-projects-recommended-for-funding-2013.pdf [Accessed 07 December 2013].

[7] M.T. Restivo, F. Chouzal, J. Rodrigues, P. Menezes, J. B. Lopes, Augmented Reality to Improve STEM Motivation, submitted to EDUCON 2014.

[8] M.T. Restivo, J. Rodrigues, F. Chouzal, P. Menezes, J. Almacinha, Online systems for training the evaluation of deviations of geometrical characteristics, submitted to International Journal of Online Engineering, 2013.

[9] M.T. Restivo and A. Cardoso, "Guest Editorial", International Journal of Online Enginering (iJOE), Vol. 8, 2012.

[10] L. Gomes and S. Bogosyan, "Current Trends in Remote Laboratories", IEEE Trans. on Industrial Electronics, 56(12), pp.47444756, 2009. http://dx.doi.org/10.1109/TIE.2009.2033293

[11] D. Oblinger and J. Oblinger,"Educating the Net Generation Introduction, Transforming education through information technologies", Educose, 2005. Available electronically at www.educause.edu/educatingthenetgen// [Accessed 07 December 2013].

[12] P. Xia, A. Lopes and M.T. Restivo, "A New Type Haptic-based Virtual Environment System for Assembly Training of Complex Products", International Journal of Advanced Manufacturing Technology, Vol. 58, Issue 1-4, pp 379-396, 2012. http://dx.doi.org/10.1007/s00170-011-3381-8

[13] A. Rojko, A. Pester and K. Jezernik. "International EPRAGMATIC network for adult engineering education". IEEE Global Engineering Education Conference (EDUCON), Amman, Jordan, pp. 34-39, 2011. http://dx.doi.org/10.1109/EDUCON. 2011.5773109

[14] A. Pester, A. Rojko and C. Maier. "Distance training of Mechatronics and Alternative technologies in European industry". International conference on e-learning on workplace, ICELW, 2011.

[15] I. Titov, O. Smirnova, A. Glotov and A. Golovin. "Remote Laser Laboratory: First Demonstration". International Journal of Online Engineering (iJOE), Vol. 8, 2012.

[16] M.T. Restivo and A. Cardoso, "Promoting Remote and Virtual labs in Portugal", International Journal of Engineering Pedagogy, SI TaT'12, Vol 3, pp 11-15, 2013.

[17] J.T. Bell \& H.S. Fogler, Low Cost Virtual Reality and its Application to Chemical Engineering - Part One", Computing and Systems Technology Division Communications, American Institute of Chemical Engineers, 18(1), 1995.

[18] P. Jain, S. Markidis, B.G. Jones, Rizwan-uddin, J. R. White, L M. Bobek, "Web-casting of Nuclear Reactor Experiments", Transactions of the American Nuclear Society, V 95, pp. 994-996, 2006.

[19] M.T. Restivo, J. Villate, F. Almeida, F. Chouzal, R. Magalhães and I. Menezes, The Michelson Interferometer: a learning object, Proceedings REV2007, Porto, Portugal, 2007.

[20] A. Cardoso, M.T. Restivo, P. Cioga, M. Delgado, J.N. Monsanto, J. Bicker, E. Nunes and P. Gil, Demonstration of Online Educational Modules with Online Experiments, Proceedings of the $9^{\text {th }}$ International Conference on Remote Engineering and Virtual Instrumentation (REV2012), IEEE Xplore, 2012.

[21] R. Azuma, Y. Baillot, R. Behringer, S. Feiner, S. Julier \& B. MacIntyre, "Recent advances in augmented reality", IEEE Com- puter Graphics and Applications, 21(6), 34-47, 2001. http://dx.doi.org/10.1109/38.963459

[22] S.Wiedenmaier, O. Oehme, L. Schmidt \& H. Luczak, "Augmented reality (AR) for assembly processes design and experimental evaluation", International Journal of Human-Computer Interaction,
$16(3)$,
497-514,
2003. http://dx.doi.org/10.1207/S15327590IJHC1603_7

[23] L.D. Xu, C. Wang, Bi, Z. and J. Yu, "AutoAssem: an automated assembly planning system for complex products", IEEE transactions on industrial informatics,Vol. 8, No. 3, 2012. http://dx.doi.org/10.1109/TII.2012.2188901

[24] Boothroyd, G., "Assembly automation and product design", Marcel Dekker, New York, 1992.

[25] Boothroyd, G., "Assembly automation and product design", Marcel Dekker, New York, 1992.

[26] A. M. Okamura, C. Richard, M. R. Cutkosky, Feeling is Believing: Using a Force-Feedback Joystick to Teach Dynamic Systems, Journal of Engineering Education, pp. 345-349, 2002.

[27] M.T. Restivo, A.M. Lopes, P.J. Xia, "'Feeling" young modulus of materials", 9th International Conference on Remote Engineering and Virtual Instrumentation (REV), IEEE Xplore, 2012.

[28] M.G. Jones, A. Bokinsky, T. Andre, D. Kubasko, A. Negishi, R. Taylor, R Superfine, Nanomanipulator applications in education: the impact of haptic experiences on students' attitudes and concepts, 10th Symp. On Haptic Interfaces For Virtual Envir. \& Teleoperator Systs. (HAPTICS'02), 2002.

[29] T. Cherrett, G. Wills, J. Price, S. Maynard and I. E. Dror, "Making training more cognitively effective: Making videos interactive." British Journal of Educational Technology no. 40 (6):1124-1134, 2009.

[30] D. Zhang, L. Zhou, R. Briggs \& J.Nunamaker, " Instructional video in e-learning: assessing the impact of interactive video on learning effectiveness", Information \& Management, 43, 15-27, 2006. http://dx.doi.org/10.1016/j.im.2005.01.004

[31] D.G.Oblinger. "The next generation of educational engagement". Journal of interactive media in education [online]. (8), 2004, http://www-jime.open.ac.uk/jime/article/view/2004-8-oblinger [Accessed 07 December 2013].

[32] R. Freedman. "What is an intelligent tutoring system?". Intelligence. 11(3), pp. 15-16, 2000. http://dx.doi.org/10.1145/ $\underline{350752.350756}$

[33] J. Noguez, and G. Huesca. "LaSiTo: A Lathe Simulated Virtual Laboratory". Proceedings of the $38^{h}$ IEEE International Conference Frontiers in Education, Saratoga Sprongs, New York, USA. IEEE Press, S2A-13-S2A-18. October, 2008.

[34] K. Muñoz, P. Mc Kevitt, T. Lunney, and J. Noguez. "Virtual Learning Environments and Intelligent Tutoring Systems - Survey of current approaches and design methodologies". Review Paper available from: http://karlamunoz.net/PhD/ReviewPaper_Kar la.pdf [Accessed 07 December 2013].

\section{AUTHORS}

M. T. Restivo is with IDMEC-Pólo FEUP and with Faculdade de Engenharia, Universidade do Porto, Rua Dr. Roberto Frias, 4200-465 Porto, Portugal (e-mail: trestivo@fe.up.pt).

A. Cardoso is with the CISUC - Centre for Informatics and Systems of the University of Coimbra, Department of Informatics Engineering of FCTUC, University of Coimbra, Polo II, 3030-290 Coimbra, Portugal (e-mail: alberto@dei.uc.pt).

This work was partially supported by the Experiment@Portugal-2012 project, funded by the Calouste Gulbenkian Foundation. This article is an extended and modified version of a paper presented at the ICL2013 Special Session "Talking about Teaching 2013" (TaT'13), held from 25 to 27 September 2013 at Kazan National Research Technological University, in Kazan, Russia. Submitted, December, 11, 2013. Published as re-submitted by the authors March, 17, 2014. 